\title{
The relationship between carotid disease and retinopathy in diabetes: a systematic review
}

\author{
Jocelyn J. Drinkwater, Timothy M. E. Davis ${ }^{*}$ id and Wendy A. Davis
}

\begin{abstract}
Background: Since studies of the relationship between carotid disease and diabetic retinopathy (DR) have shown apparent inconsistencies, the aim of this study was to conduct a systematic review of available published data.

Methods: Electronic databases were searched independently by two reviewers, according to an iterative protocol, for relevant articles. The search term used was "diabetes AND (carotid disease OR intima-media OR carotid plaque OR carotid stenosis OR carotid arterial disease OR carotid artery disease OR carotid atherosclerosis) AND (retinopathy OR diabetic retinopathy)".
\end{abstract}

Results: From 477 publications, 14 studies were included. There were differences in the variables used as markers of carotid disease and DR across the included studies. Ten studies used carotid disease as the dependent variable, and the remainder used DR. All but one study involved cross-sectional data. Most studies reported a statistically significant association between at least one parameter of carotid disease as assessed by ultrasound and DR presence or severity. Only four studies reported no significant association. A common limitation was the use of convenience participant sampling.

Conclusions: There appears to be an increased likelihood of DR when there is ultrasonographic evidence of carotid disease, and vice versa. The available studies suggest that there may be a direct relationship between DR and carotid macrovascular disease and/or that these complications co-exist due to shared risk factors. If carotid disease is detected, retinal assessment should be performed. If DR is identified, intensive cardiovascular disease risk management should be considered. Additional longitudinal studies are needed to assess the directionality of the association.

Keywords: Diabetes mellitus, Diabetic retinopathy, Carotid disease, Carotid intima-media, Carotid plaque, Carotid atherosclerosis

\section{Background}

Diabetic retinopathy (DR) is a common microvascular complication affecting over one-third of people with diabetes mellitus [1]. It is one of the leading causes of moderate or severe visual impairment globally [2]. Known modifiable risk factors comprise hyperglycemia, hypertension and dyslipidemia [1, 3], but the pathophysiology of DR is not fully understood. Several biochemical mechanisms have been suggested including increased

*Correspondence: tim.davis@uwa.edu.au

Medical School, The University of Western Australia, Fremantle Hospital, P.

O. Box 480, Fremantle, WA 6959, Australia oxidative stress, inflammation, neurodegeneration and upregulation of vascular endothelial growth factor (VEGF) [4]. Despite screening programs aimed at early detection, there are few treatments for DR and most can only be used to prevent worsening of established disease [5]. There is, therefore, a need for improved understanding of the epidemiology of DR including risk factors so that it can be identified earlier, new preventive strategies and treatments developed, and vision loss prevented or delayed.

Diabetic retinopathy is characterised by vascular lesions including microaneurysms, hemorrhages and exudates [4]. Less severe DR typically refers to mild to 
moderate non-proliferative diabetic retinopathy (NPDR), while more severe DR generally comprises severe NPDR or proliferative diabetic retinopathy (PDR) which have a greater effect on vision $[4,6]$. The Early Treatment Diabetic Retinopathy Study protocol is commonly used to assess the severity of DR [6-10]. According to this scheme, mild NPDR consists of at least one microaneurysm without evidence of other pathological lesions [6]. When NPDR progresses to PDR there is evidence of neovascularisation [6].

Appropriately intensive management of hyperglycemia and hypertension reduces the risk of DR [3, 4]. Of the few available specific treatments, intravitreal anti-VEGF agents, such as aflibercept, ranibizumab and bevacizumab, are now considered as a first-line treatment for vision-threatening DR but not all patients respond and these therapies are costly $[5,11]$. Laser photocoagulation, which used to be the first-line treatment, and intravitreal corticosteroids are also used to treat severe DR [3-5, 11]. In type 2 diabetes (T2D), fenofibrate is a treatment that can prevent DR progression. The Fenofibrate Intervention and Event Lowering in Diabetes (FIELD) study, which recruited 9795 participants, showed fenofibrate reduced the need for laser treatment and, in those with pre-existing DR, the risk of progression [12]. The Action to Control Cardiovascular Risk in Diabetes (ACCORD) Eye study, which involved 10,251 participants, showed that those in the fenofibrate and statin arm had lower odds of DR progression after 4 years than those in the placebo and statin only arm [13]. Nevertheless, there is still a residual risk of DR progression despite these interventions.

Carotid arterial disease is a major macrovascular complication of diabetes. It is generally assessed by ultrasound which can detect atherosclerotic plaque and quantify intima-media thickness (IMT; see Additional file 1: Figure S1) [14, 15]. The Mannheim consensus considers plaque to be a focal structure that encroaches into the arterial lumen of at least $0.5 \mathrm{~mm}$ or $50 \%$ of the surrounding IMT value, or demonstrates a thickness of $\geq 1.5 \mathrm{~mm}$ as measured from the media-adventitia interface to the intima-lumen interface [16]. The degree of stenosis associated with a plaque is expressed as a percentage of the lumen diameter. The IMT can be measured in the common carotid artery (CCA), at the bifurcation and in the internal carotid artery (ICA) [16]. Carotid disease is associated with stroke and cardiovascular disease $[14,15]$. A review of six studies found an increased risk of cardiovascular events in people with a higher CCA IMT [17]. The presence and number of plaques have also been associated with greater risk of cardiovascular disease, but the combination of both increased CIMT and plaque may be a better measure [18]. People with an IMT $\geq 1 \mathrm{~mm}$ and those with high grade stenosis are considered to be at very high risk of cardiovascular events [14].

Microvascular disease in diabetes has been associated with macrovascular disease, a relationship that may reflect shared risk factors [19]. However, the specific association between carotid arterial disease as a manifestation of proximal macrovascular disease and DR as a form of microangiopathy is not well established. As the carotid artery supplies blood to the retina, it is possible carotid disease has a direct effect on the development of DR. The aim of the present systematic review was, therefore, to assess the evidence linking carotid disease and DR in people with diabetes.

\section{Methods}

\section{Search strategy and selection criteria}

An iterative protocol developed according to the Preferred Reporting Items for Systematic Review and MetaAnalysis (PRISMA) Statement was followed [20]. The electronic databases Embase, PubMed and MEDLINE were searched. The Boolean search term used was "diabetes AND (carotid disease OR intima-media OR carotid plaque OR carotid stenosis OR carotid arterial disease OR carotid artery disease OR carotid atherosclerosis) AND (retinopathy OR diabetic retinopathy)". Studies were eligible for inclusion if they specifically assessed the relationship between carotid disease and DR using statistical analyses appropriate to the study design with relevant results clearly displayed and an effect size given. In cases where studies assessed the relationship but did not give effect sizes or clear results, the authors were contacted and studies were included if this information was provided. A minimum sample size of 50 participants (to reduce likelihood of type II error) and a statistical analysis that, as a minimum, assessed the effect of age and sex on the association between carotid disease and DR were required. Studies were restricted to those reported in English and conducted in adults. Those not specifying diabetes type and the criteria for determining carotid disease and DR were excluded. In vitro and animal studies, case studies, case series and conference abstracts were also excluded. The search included articles published to end-2019. The summary measures used were those reported in individual studies.

Two reviewers (JD and WD) independently conducted the literature search and reviewed all the articles assessing eligibility and extracting required information. The data from included studies were entered into pre-defined fields including the country where the research was conducted, year(s) the data were collected, study design, aims, definitions, type of diabetes, sample size, methods, results, covariates and limitations. The reference lists of the included articles were reviewed to ensure 
articles that met the inclusion criteria were not inadvertently excluded due to search terms. The risk of bias of each study was assessed according to guidelines in the Cochrane handbook [21]. The quality of the individual studies was assessed using the National Heart, Lung, and Blood Institute Quality Assessment Tool for Observational and Cross-Sectional Studies [22]. Although a metaanalysis was considered, this was not appropriate.

\section{Results}

The process of article selection is summarised in Fig. 1. The search identified 477 publications. After excluding duplicates, those not available in English and those of inappropriate format (notes, editorials etc.), 228 abstracts were assessed for relevance and 43 full-text articles were suitable for further evaluation. We emailed authors of four publications for further information, but only received a response from one [23] and excluded the three studies for which no response was received [24-26]. No further papers were identified from checking reference lists of relevant papers. The final number of journal articles included in the review was 14 (see Fig. 1).

These 14 publications were from 10 different countries including three from South Korea [10, 27] and two each from Spain [7, 28] and Brazil [23, 29]. The Spanish papers were from the same study but one included participants with type 1 diabetes (T1D) [28] while the other included people with T2D [28]. The Brazilian publications were also from the same study sample, the Rio de Janiero Type 2 Diabetes Cohort Study (RDJ), but assessed different outcomes and so both publications were included [23, 29]. Most of the studies were cross-sectional and only one (the RDJ) included longitudinal data [23]. The characteristics of the included studies are shown in Table 1. The sample size ranged from 87 to 1607 participants. Most study samples comprised people with (T2D) but three included participants with T1D [7, 30,31].

There was heterogeneity between the studies included in our review. There were noticeable differences in the variables used as markers of carotid disease and DR, as described in Table 2. Measures used to assess carotid disease included measurement of intima media thickness (IMT), plaque, stenosis, or a combination of these. In addition to using different variables as markers of carotid disease, there were also differences in analyses as studies either used continuous variables, a clinically relevant level to split the data into two groups, or percentiles. Two studies assessed DR severity $[7,28]$ and the RDJ assessed

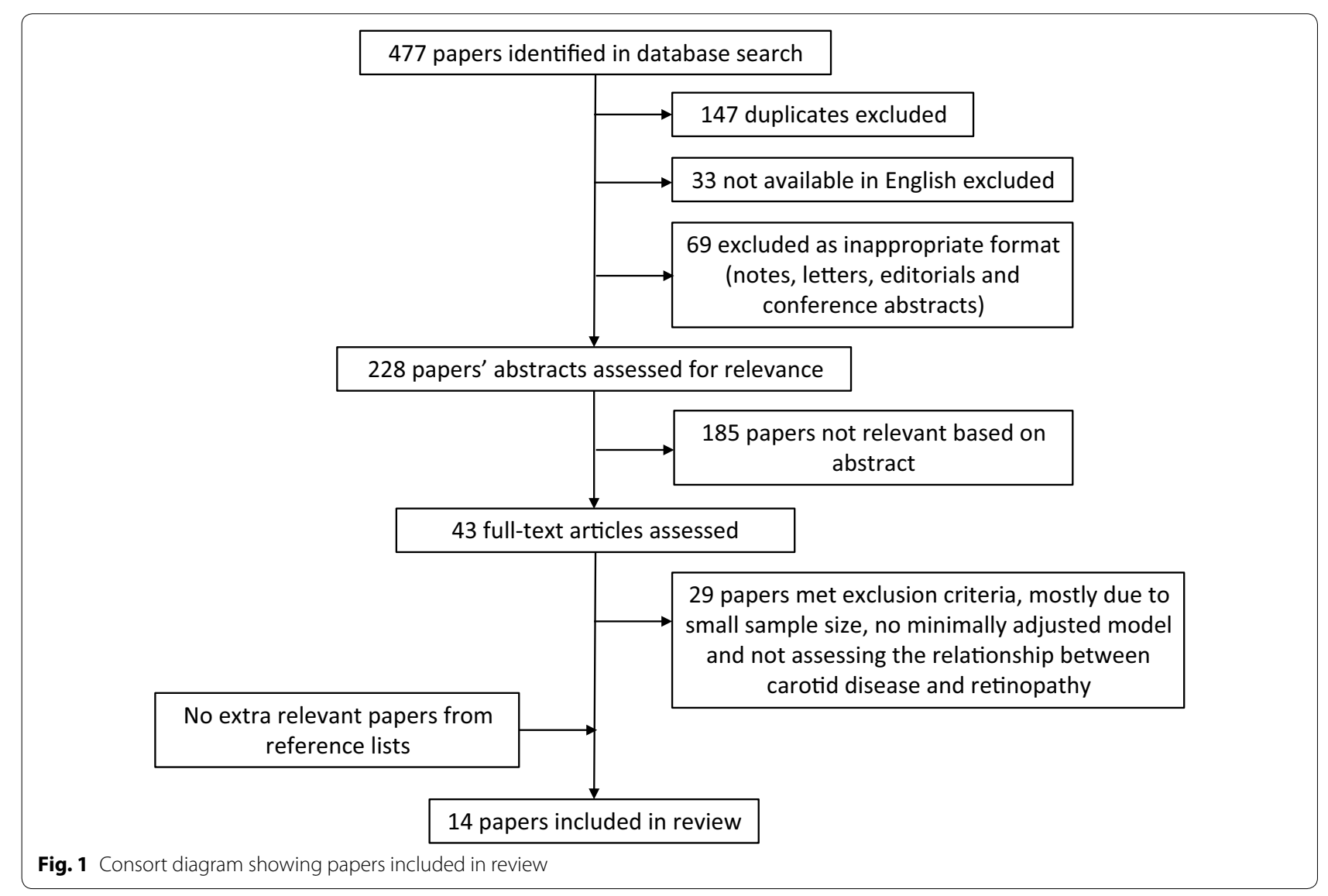




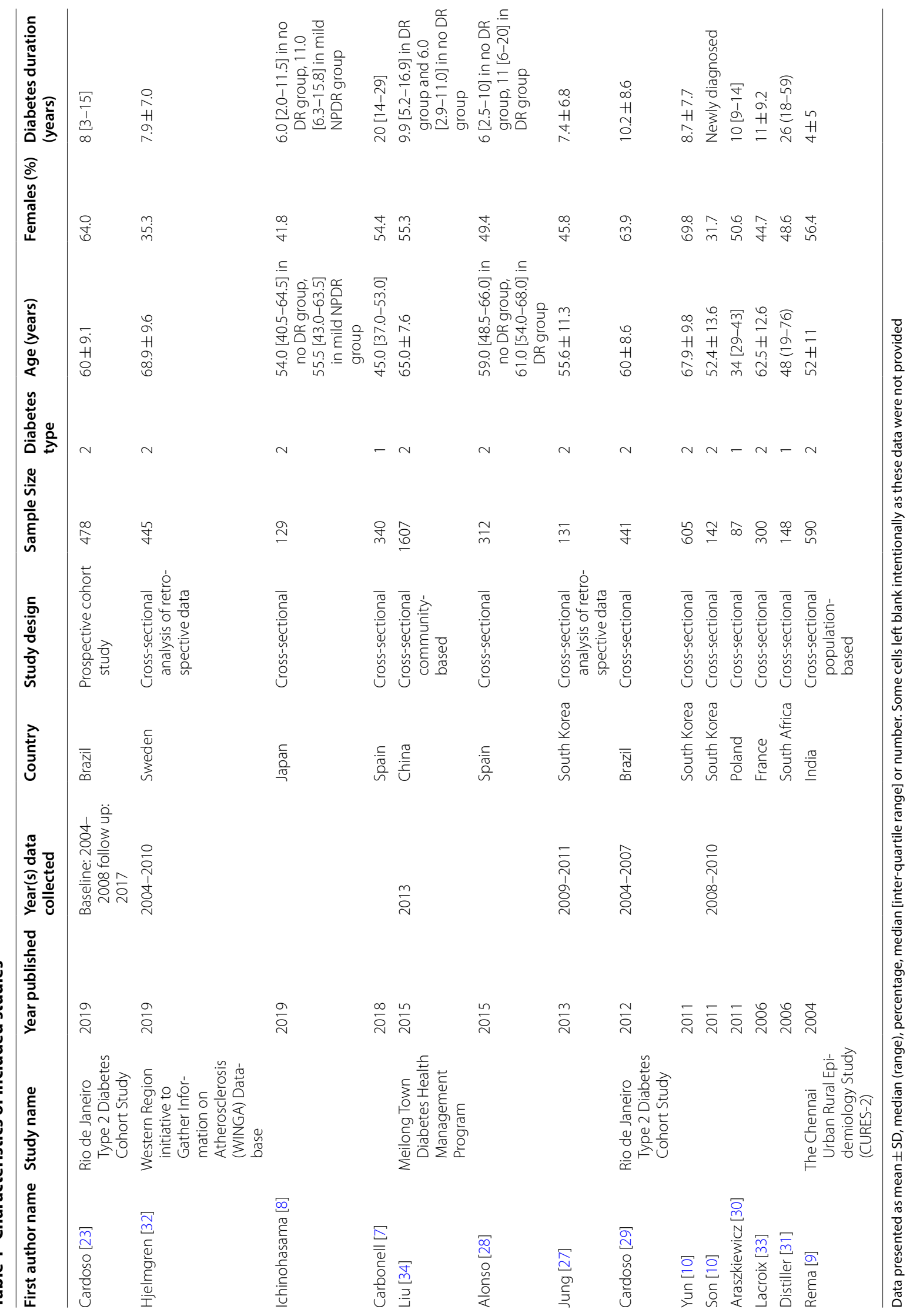




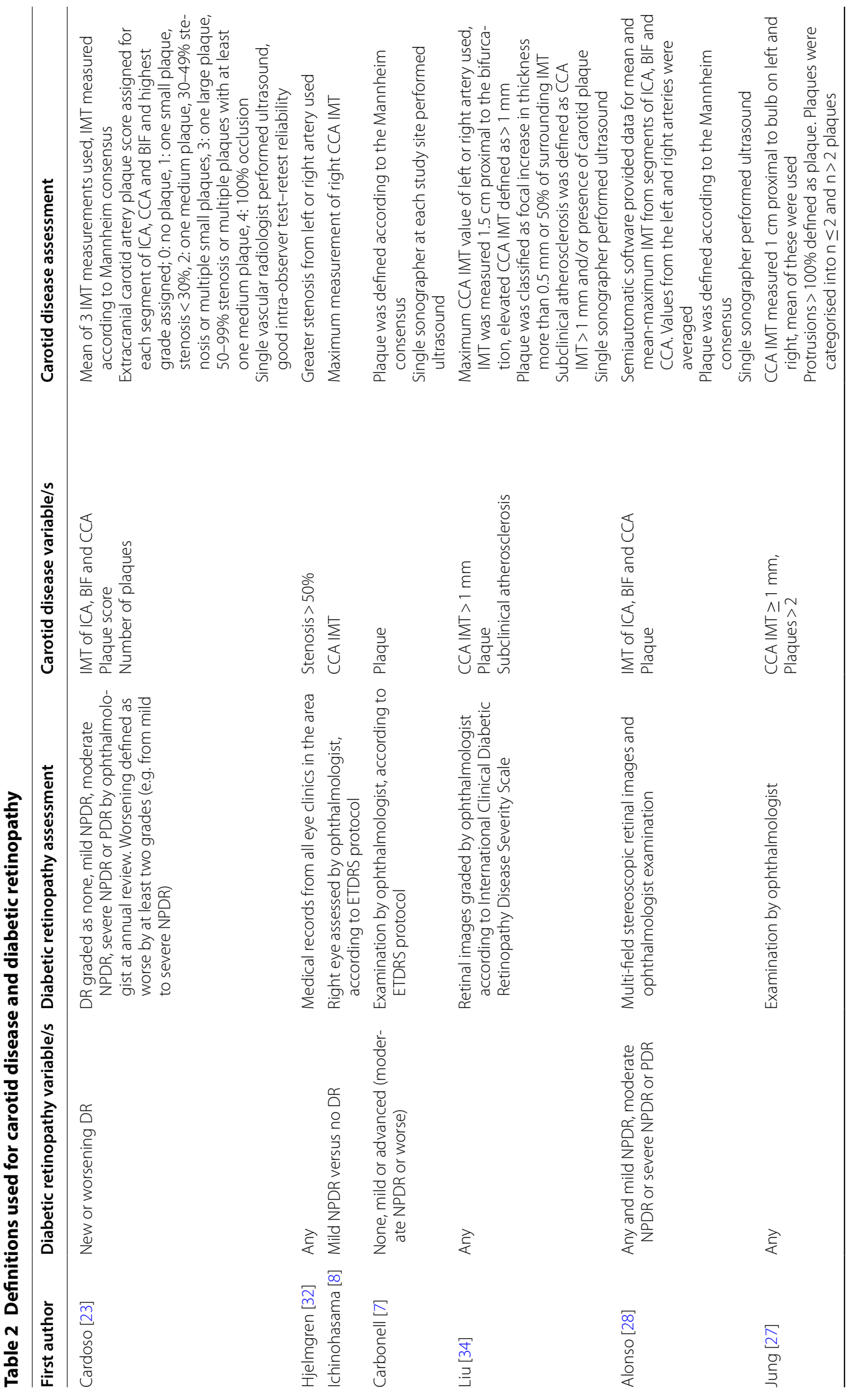




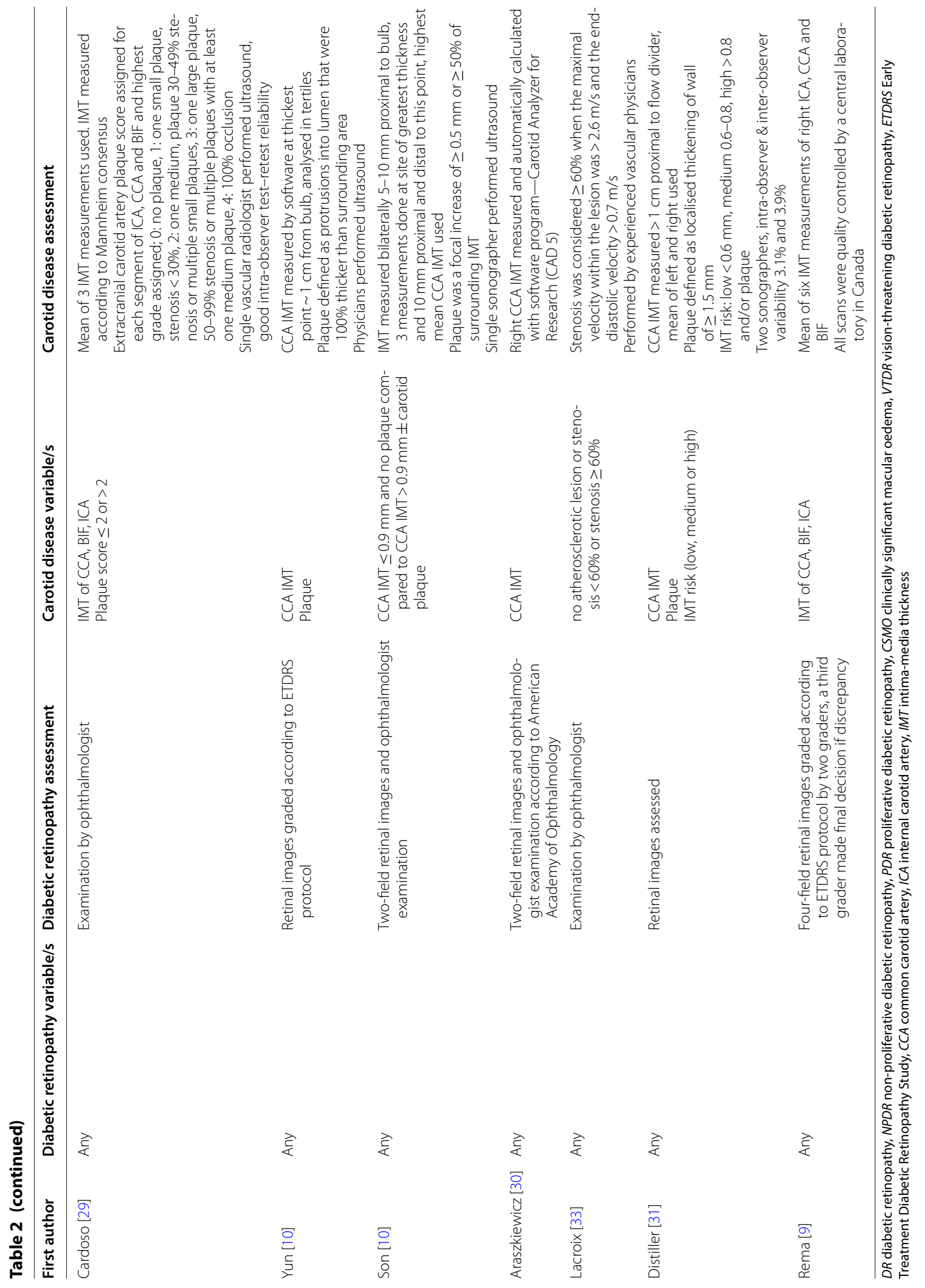


new or worsening DR in their longitudinal analysis [23]. While most other studies determined the severity of DR in their participants, a dichotomous variable (DR absent or present) was used to assess the association with carotid disease. The methods by which DR was graded also varied between the studies. Four specifically stated that the ETDRS grading system was used and one used the International Clinical Diabetic Retinopathy Disease Severity Scale, but many did not give sufficient detail often simply stating that an ophthalmologist graded DR (see Table 2). Due to the significant methodological differences between these studies, a meta-analysis was not appropriate.

The methods, results and limitations of these studies are summarised in Table 3. Ten studies used carotid disease as the dependent variable in analysis [7, 10, 23, $27-29,31-34$ ] and the remaining four used DR as the dependent variable $[8-10,30]$. However, as only one study had a longitudinal component (with carotid disease as dependent variable), the directionality of any association was not able to be determined. The results from the cross-sectional studies suggest that there is some association between the two complications (see Table 4). In general, there was a statistically significant relationship between one or more measure of carotid disease and DR. Four of the 14 studies reported no statistically significant association between any carotid disease variable and any DR variable [10, 23, 30, 32].

The four main carotid variables identified were CCA IMT, other measures of IMT including combinations with CCA IMT, plaque or stenosis, and other carotid disease that mostly comprised a combination of carotid variables. Half of the studies assessed only one carotid disease variable $[7-10,30,32,33]$ while the other half assessed more than one carotid disease variable [10, 23, $27-29,31,34]$. Of the seven studies which assessed multiple such variables, three found a significant relationship between DR and carotid plaque only [28, 29, 31], one reported an association with CCA IMT only [27], two reported no significant association $[10,23]$ and one reported a significant association with all carotid variables assessed [34]. Of all included studies, two reported that DR was significantly associated with a combined measure of plaque and IMT [10, 34]. Nine of the 14 papers specifically assessed the relationship with plaque/ stenosis and DR and six reported a significant association $[7,28,31,33,34]$. Plaque was often significantly associated with carotid disease, but this finding was not consistent across all studies.

Ten studies assessed the relationship with CCA IMT and DR. Three of these found a significant association, two reported CCA IMT was associated with any DR [27, 34] and one reported an association with mild NPDR [8].
Interestingly, the two studies that reported an association between any DR and CCA IMT used a cut-off point for CCA IMT of $\geq 1 \mathrm{~mm}[27,34]$ while those that reported no association assessed CCA IMT as a continuous variable or split the IMT by tertiles [10, 28-31]. Some of these studies may have had insufficient statistical power, especially as one comprised just 87 participants [30], and only one provided a sample size calculation [28]. Four studies assessed other measures of IMT, of which one determined an association between DR and internal carotid artery (ICA) IMT [28] and one reported that the mean IMT of the ICA, CCA and bifurcation was associated with DR [9]. There did not appear to be a single marker of carotid disease that consistently identified an increased likelihood of DR presence or severity. However, most studies have shown that there is a relationship between at least one measure of carotid disease and DR.

While most studies showed a significant association between carotid disease and DR, four studies reported no significant relationship. Three of these were of good quality $[10,23,30]$, while one was of poor quality [32]. The study by Araszkiewicz et al. had a small sample size compared to the other studies and excluded those with carotid stenosis $>50 \%$; this probably also excluded those with a high common carotid artery (CCA) IMT which may explain the lack of association [30]. Hjelmgren et al. assessed the relationship with stenosis and defined stenosis as a narrowing of $>50 \%$, excluding less severe cases [32]. In the study by Yun et al., CCA IMT was analysed by tertiles, the highest of which ranged from 0.79 to $1.30 \mathrm{~mm}$, including those without clinically significant intima-media thickening of $\geq 1 \mathrm{~mm}$ [10]. However, this study also assessed the relationship with carotid stenosis and found no significant association [10]. The longitudinal RDJ study found no statistically significant association between any measure of carotid disease and new or worsening DR, but this sample was outpatient clinicbased [23]. The lack of association seen in some studies may be due to methodological differences.

A common limitation was that most studies used convenience sampling and recruited participants from hospitals and clinics. This increases the likelihood of selection bias, as these participants are more likely to be complex and therefore not representative of the general population of people with diabetes. There was, however, one population-based study [9] and one study that recruited participants from a community-based health program [34]. Measurement bias for DR and carotid disease was another limitation in many studies, with few studies reporting on inter- or intra-rater agreement or quality control measures. Other limitations and potential sources of bias included assessment of only one eye or one carotid artery, and exclusion of participants with a 


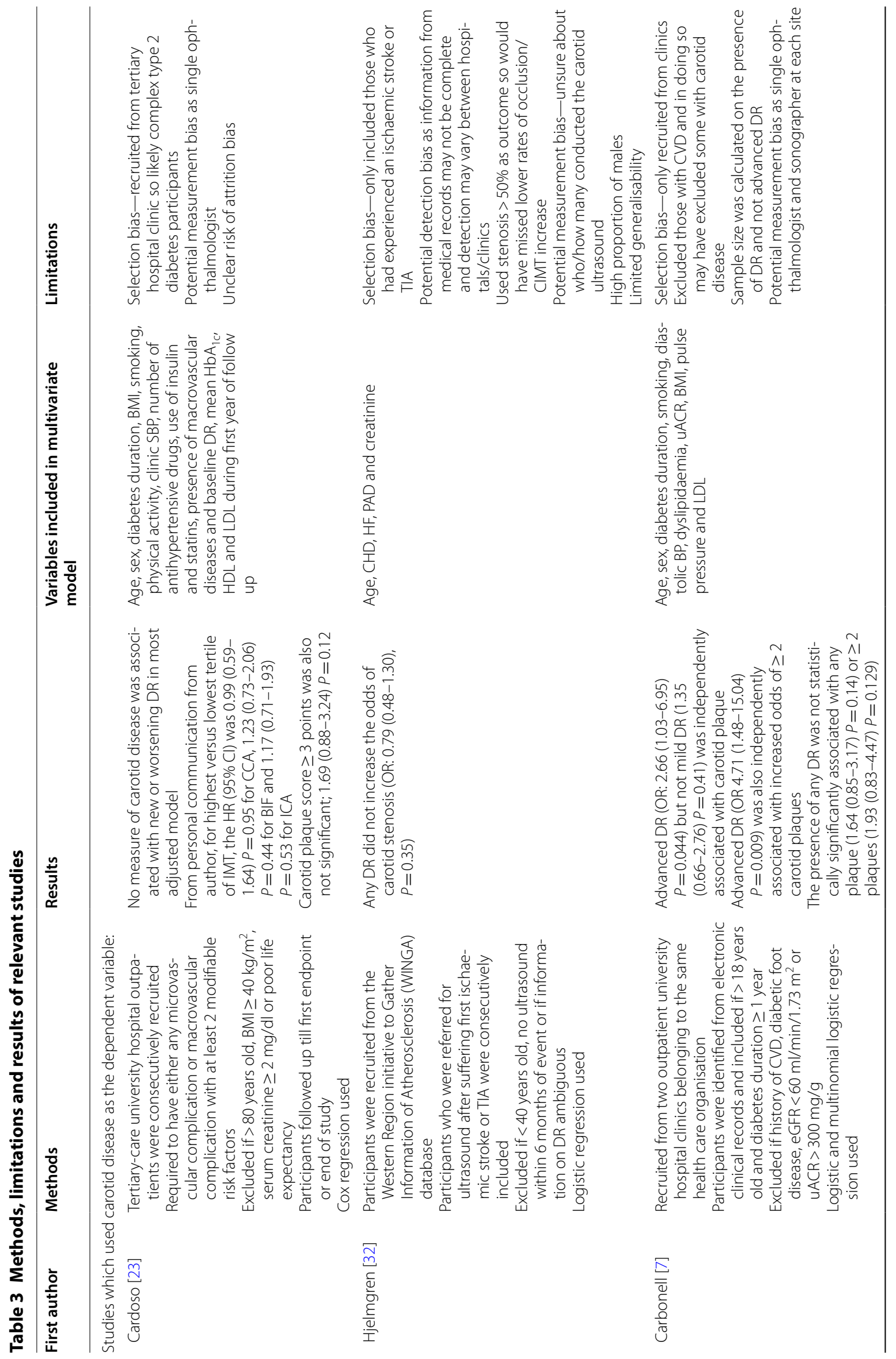




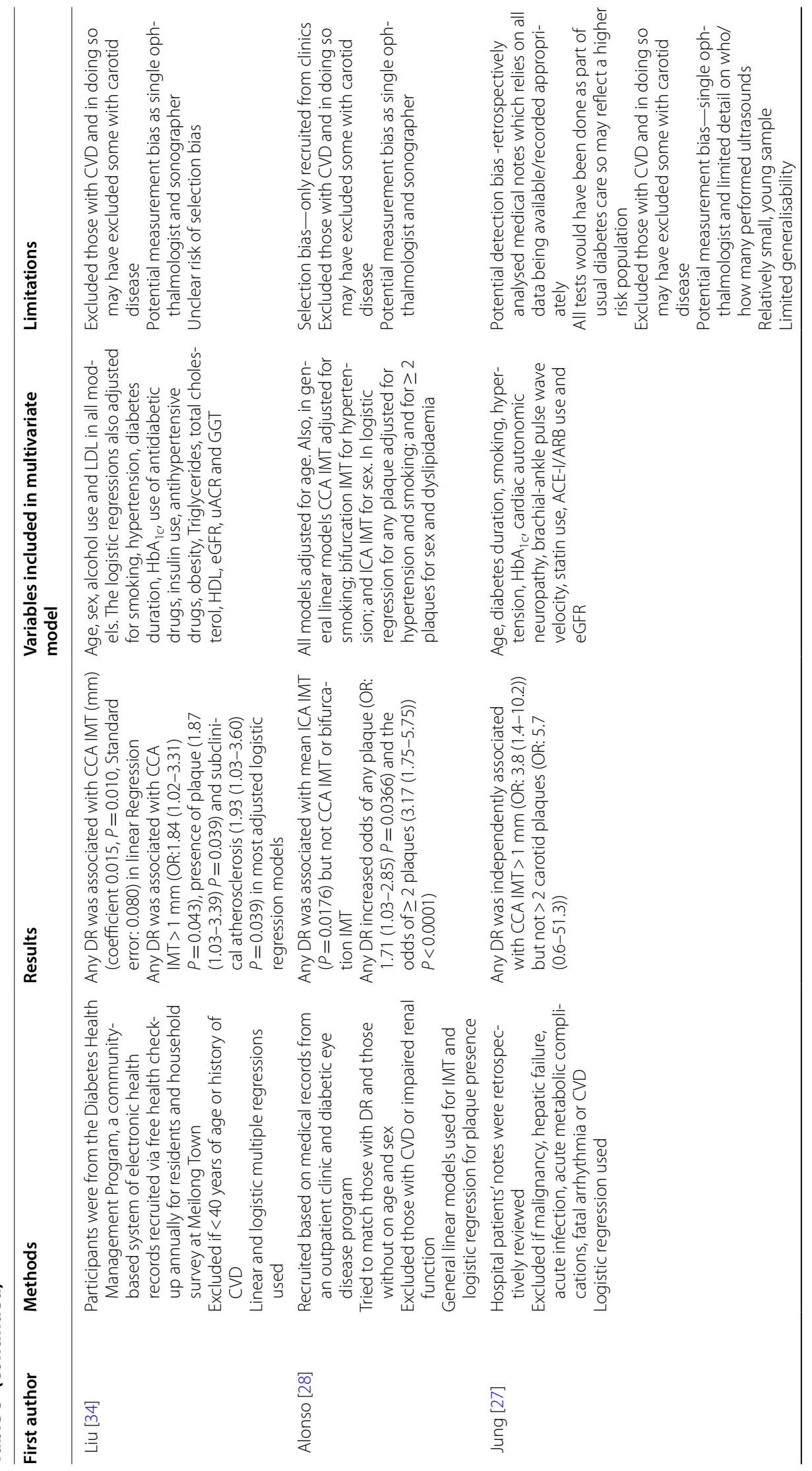




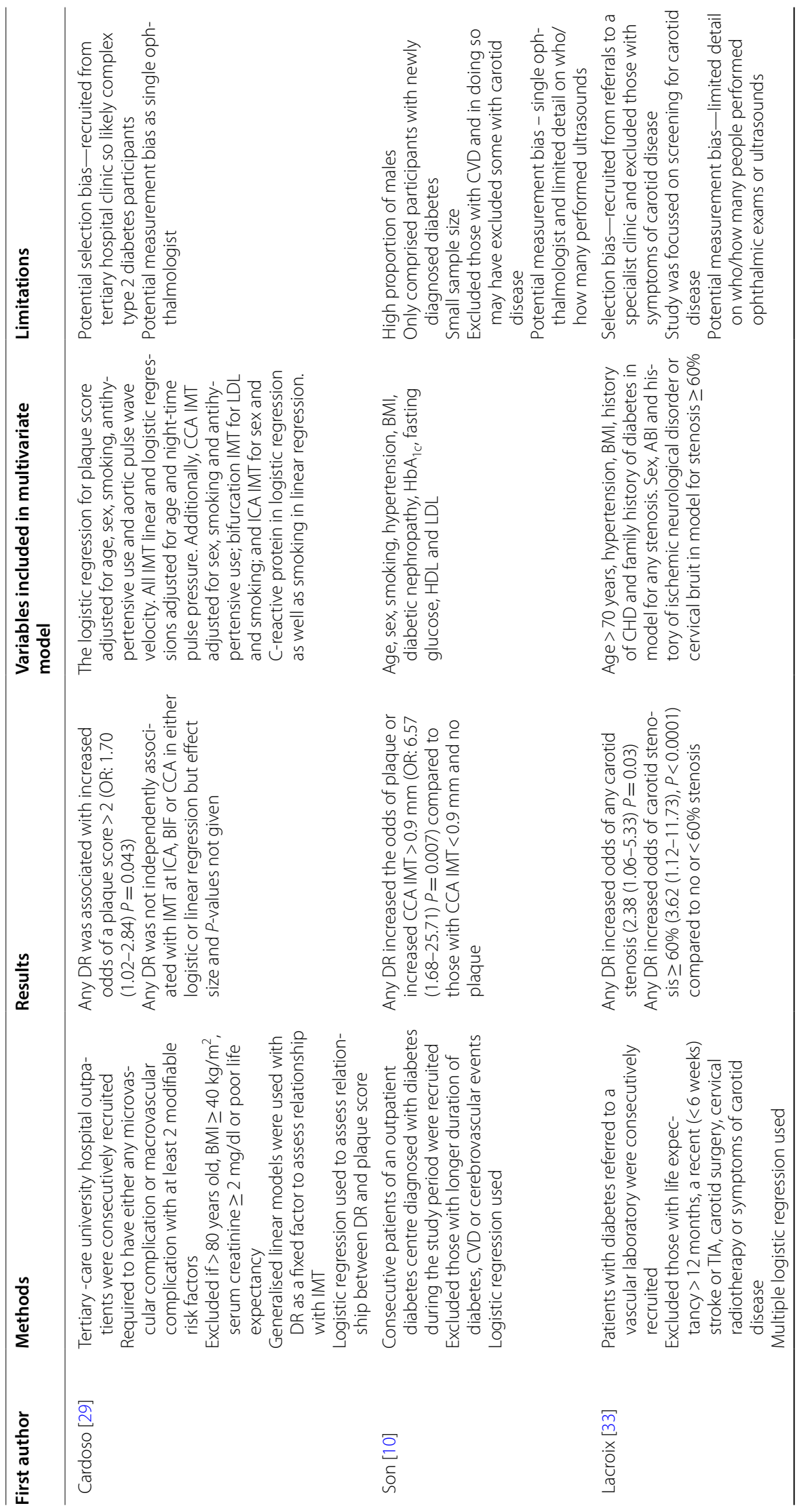




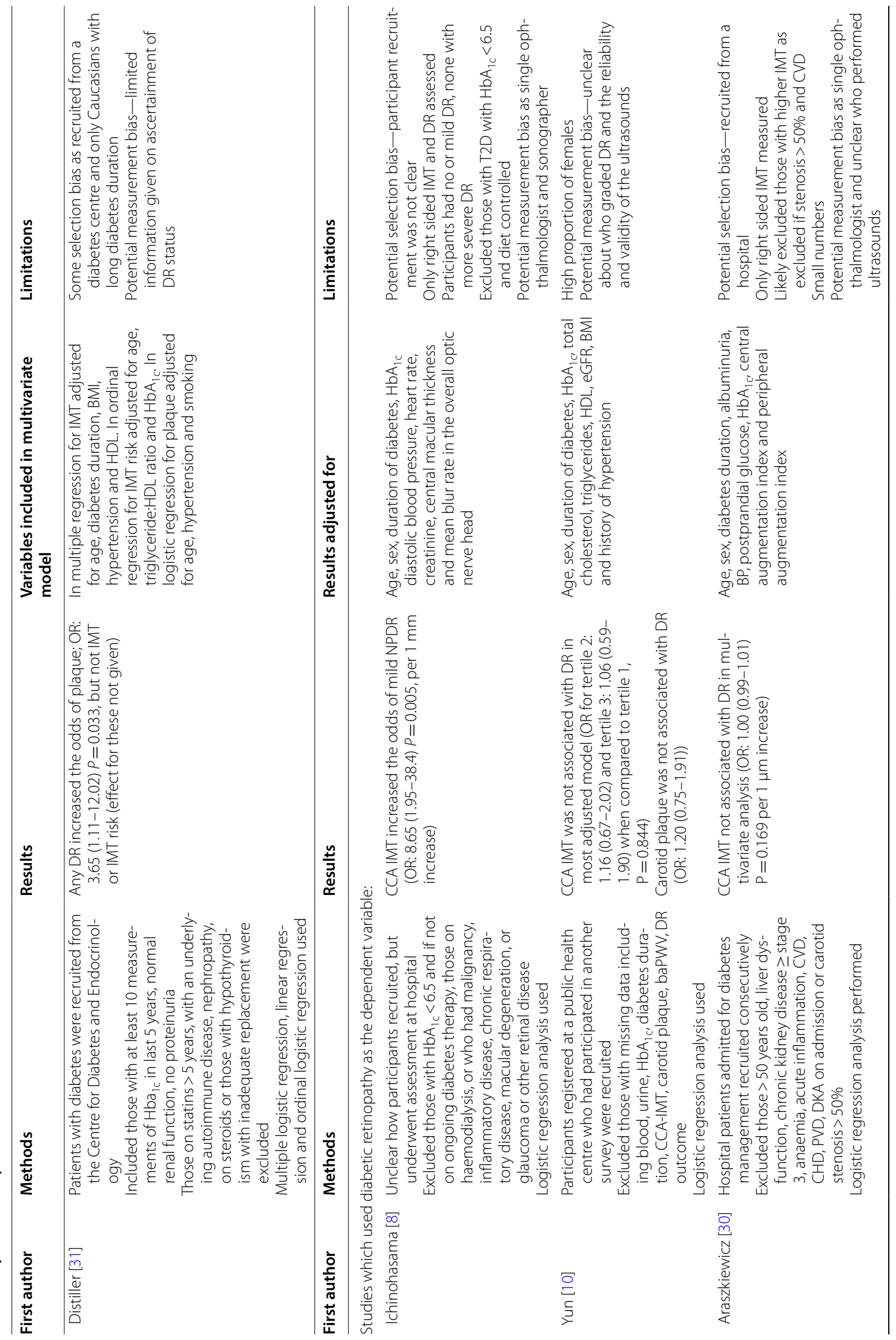




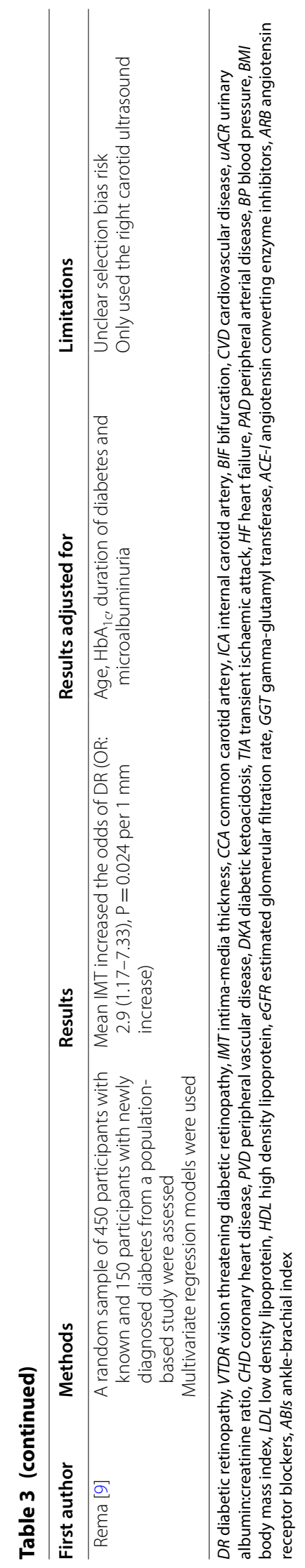


Table 4 Summary showing which studies reported significant and non-significant associations between carotid disease and retinopathy

\begin{tabular}{|c|c|c|c|}
\hline \multicolumn{2}{|c|}{ Carotid disease variable } & \multirow{2}{*}{$\begin{array}{l}\text { Any diabetic retinopathy } \\
\text { Alonso [28] } \\
\text { Cardoso [29] } \\
\text { Distiller [31] } \\
\text { Yun [10] } \\
\text { Araszkiewicz [30] }\end{array}$} & \multirow{2}{*}{$\begin{array}{l}\text { Other diabetic retinopathy } \\
\text { Alonso [28]_DR severity } \\
\text { Cardoso [23] — new or worsening DR }\end{array}$} \\
\hline CCA IMT & Non-significant & & \\
\hline & Significant & $\begin{array}{l}\text { Liu [34] } \\
\text { Jung [27] }\end{array}$ & Ichinohasama [8]—mild NPDR \\
\hline \multirow[t]{2}{*}{ Other IMT } & Non-significant & $\begin{array}{l}\text { Alonso [28]—BIF } \\
\text { Cardoso [29]—ICA \& BIF }\end{array}$ & $\begin{array}{l}\text { Alonso [28] —ICA \& BIF, DR severity } \\
\text { Cardoso [23] —ICA \& BIF, new or worsening DR }\end{array}$ \\
\hline & Significant & $\begin{array}{l}\text { Alonso [28]_ICA } \\
\text { Rema [9]—Mean IMT }\end{array}$ & \\
\hline \multirow[t]{2}{*}{ Plaque/Stenosis } & Non-significant & $\begin{array}{l}\text { Hjelmgren [32] } \\
\text { Carbonell [7] } \\
\text { Jung [27] } \\
\text { Yun [10] }\end{array}$ & $\begin{array}{l}\text { Alonso [28]_DR severity } \\
\text { Cardoso [23]—new or worsening DR }\end{array}$ \\
\hline & Significant & $\begin{array}{l}\text { Liu [34] } \\
\text { Alonso [28] } \\
\text { Lacroix [33] } \\
\text { Distiller [31] } \\
\text { Cardoso [29] }\end{array}$ & Carbonell [7]_advanced DR \\
\hline \multirow[t]{2}{*}{ Other } & Non-significant & Distiller [31]—IMT risk & \\
\hline & Significant & $\begin{array}{l}\text { Liu [34] —any plaque and/or CCA IMT }>1 \mathrm{~mm} \\
\text { Son [10] —any plaque and/or CCA IMT }>0.9 \mathrm{~mm}\end{array}$ & \\
\hline
\end{tabular}

BIF bifurcation, CCA common carotid artery, DR diabetic retinopathy, ICA internal carotid artery, IMT intima-media thickness

history of cardiovascular disease and thus at relatively high risk of carotid disease. Many studies did not report their response rate. The quality of the individual studies is shown in Additional file 1: Table S1. Overall, five studies were of poor quality [8,30-33], one fair quality [27] and the remaining eight were of good quality $[7,9,10,23$, $28,29,34]$. There were no conflicts of interest identified in any of the studies.

\section{Discussion}

This is the first systematic review to assess the relationship between carotid arterial disease and DR. In most included studies there was a statistically significant association between at least one carotid disease parameter and DR presence or severity as assessed from either an increased risk of DR in the presence of carotid disease or an increased risk of carotid disease in people with known DR. No specific carotid disease variable was consistently associated with DR. Although this may reflect significant methodological differences between the studies, most that assessed the relationship between carotid stenosis/plaque and DR reported a significant association. In addition, as only one study utilised longitudinal data and found no association, the directionality of this relationship remains unknown.

There is evidence that macrovascular disease is associated with the microvascular complications of diabetes.
A recent meta-analysis has shown that DR is associated with an increased risk of stroke [35]. Diabetic retinopathy has also been shown to increase cardiovascular disease risk [36], and the severity and progression of DR was associated with cardiovascular disease in the ACCORD study [37]. A significant association between carotid disease and changes in the retinal microvasculature has also been found in adolescents with T1D [38]. Diabetic retinopathy has also been associated with other markers of peripheral arterial disease [39], peripheral vascular disease in T1D [40], and arterial stiffness [41].

The mechanisms underlying the relationship between carotid disease and DR are not well established, although there are several theories. First, the "common soil" hypothesis suggests that microvascular and macrovascular complications share risk factors including hyperglycemia, dyslipidemia and hypertension $[19,29,42]$. The Hoorn Diabetes Care System cohort study also showed that glycaemic variability was associated with both microvascular and macrovascular disease [43]. Second, it has been suggested that signs of microvascular damage in the eye could reflect concurrent microcirculatory disease in the heart and major arteries [36]. One study found that the presence of DR was associated increased neovascularisation in the vasa vasorum of the carotid artery, although there were no differences in IMT or carotid plaque by DR status [44]. Nevertheless, increased 
neovascularisation of the vasa vasorum has been associated with atherosclerosis and plaque in another study [45]. Although microvascular damage may be a potent underlying cause of macrovascular disease [46], we cannot evaluate this from the studies included in this review as the only longitudinal study assessed whether carotid disease was associated with new or worsening DR, and thus whether macrovascular disease affected microvascular complications.

Lastly, proximal macrovascular disease may directly affect the microvasculature. Interestingly, almost half of the studies in this review excluded participants with known cardiovascular disease, which is a common complication of diabetes. Of these, most reported a significant association between DR and carotid disease [7, 10, $27,28,34]$, although one found no association [30]. As there were still statistically significant associations in the absence of known cardiovascular disease, that there may be more to the relationship between carotid disease and DR than simply long term exposure to shared risk factors, supporting a direct relationship between carotid disease and DR.

The presence of stenosis or plaque was more often significantly associated with DR than other measures of carotid disease. As the carotid artery supplies the ophthalmic artery, it is possible that microemboli or plaque fragments from the carotid could dislodge and travel to the retina [47] thus contributing to the microvascular occlusion and ischaemia that occur in DR. Alternatively, carotid stenosis has a greater effect on the blood flow through the carotid artery than thickening measured by IMT. It is plausible that significant stenosis causing disruption of carotid blood flow could impact the blood supply to the retina. Improved retinal blood flow assessed by optical coherence tomography angiography has been reported in participants with carotid stenosis $>70 \%$ after carotid endarterectomy [48], and there is evidence that vision improves after carotid endarterectomy [49]. However, as some studies found that IMT was independently associated with DR, more than one mechanism is likely with a combination of common soil and direct relationships.

\section{Conclusions}

We found that there is insufficient published evidence to determine the nature, including the directionality, of the relationship between DR and carotid disease. Well conducted longitudinal studies are required to determine the direction of this association. A significant association was reported in most evaluable studies, but whether these two complications are independent but co-exist or if one contributes to the other can only be determined by well-conducted longitudinal studies. Nevertheless, our findings have clinical implications. Should carotid atherosclerosis or stenosis be detected in an individual with diabetes, we recommend that retinal examination is performed and, conversely, intensified cardiovascular risk management should be considered if DR is detected.

\section{Supplementary information}

Supplementary information accompanies this paper at https://doi. org/10.1186/s12933-020-01023-6.

Additional file 1: Figure S1. Diagram of a carotid artery with plaque at the bifurcation. Table $\mathbf{S 1}$. The quality of the included studies.

Abbreviations

ACCORD: Action to Control Cardiovascular Risk in Diabetes; CCA: Common carotid artery; DR: Diabetic retinopathy; FIELD: Fenofibrate Intervention and Event Lowering in Diabetes; ICA: Internal carotid artery; IMT: Intima media thickness; NPDR: Non-proliferative diabetic retinopathy; PRISMA: Preferred Reporting Items for Systematic Review and Meta-Analysis; RDJ: Rio de Janiero Type 2 Diabetes Cohort Study; T1D: Type 1 diabetes; T2D: Type 2 diabetesVEGF- vascular endothelial growth factor

\section{Acknowledgements}

We would like to thank Professor Gil Salles for providing unpublished results from the Rio de Janiero Type 2 Diabetes Cohort Study.

\section{Authors' contributions}

JD developed the protocol, independently conducted the literature search and wrote the first draft of the manuscript, WD independently conducted the literature search, revised and edited the manuscript. TD gave clinical guidance, and revised and edited the manuscript. All authors read and approved the final manuscript.

\section{Funding}

JD is supported by the Warren Jones UWA Postgraduate Research Scholarship and Australian Government Research Training Program Scholarship. TD is supported by a Medical Research Future Fund Practitioner Fellowship.

Availability of data and materials

Not applicable.

Ethics approval and consent to participate

Not applicable.

Consent for publication

Not applicable.

Competing interests

The authors declare that they have no competing interests.

Received: 22 February 2020 Accepted: 25 April 2020

Published online: 06 May 2020

References

1. Yau JWY, Rogers SL, Kawasaki R, Lamoureux EL, Kowalski JW, BekT, et al. Global prevalence and major risk factors of diabetic retinopathy. Diabetes Care. 2012;35(3):556-64. https://doi.org/10.2337/dc11-1909.

2. Flaxman SR, Bourne RRA, Resnikoff S, Ackland P, Braithwaite T, Cicinelli $\mathrm{MV}$, et al. Global causes of blindness and distance vision impairment 1990-2020: a systematic review and meta-analysis. Lancet Glob Health. 2017;5(12):e1221-34. https://doi.org/10.1016/\$2214-109X(17)30393-5.

3. Stitt AW, Curtis TM, Chen M, Medina RJ, McKay GJ, Jenkins A, et al. The progress in understanding and treatment of diabetic retinopathy. Prog 
Retin Eye Res. 2016;51:156-86. https://doi.org/10.1016/j.preteyeres 2015.08.001.

4. Cheung N, Mitchell P, Wong TY. Diabetic retinopathy. Lancet. 2010;376(9735):124-36. https://doi.org/10.1016/S0140-6736(09)62124-3.

5. Wang W, Lo ACY. Diabetic retinopathy: pathophysiology and treatments. Int J Mol Sci. 2018;19(6):1-14. https://doi.org/10.3390/ijms 19061816.

6. Early Treatment Diabetic Retinopathy Study Research Group. Early Treatment Diabetic Retinopathy Study design and baseline patient characteristics. ETDRS report number 7. Ophthalmology. 1991;98(5):741-56.

7. Carbonell M, Castelblanco E, Valldeperas X, Betriu À, Traveset A, GranadoCasas $\mathrm{M}$, et al. Diabetic retinopathy is associated with the presence and burden of subclinical carotid atherosclerosis in type 1 diabetes. Cardiovasc Diabetol. 2018;17(66):1-10. https://doi.org/10.1186/s1293 3-018-0706-z.

8. Ichinohasama K, Kunikata H, Ito A, Yasuda M, Sawada S, Kondo K, et al. The relationship between carotid intima-media thickness and ocular circulation in type-2 diabetes. J Ophthalmol. 2019;2019:1-8. https://doi. org/10.1155/2019/3421305

9. Rema M, Mohan V, Deepa R, Ravikumar R. Association of carotid intimamedia thickness and arterial stiffness with diabetic retinopathy. Diabetes Care. 2004;27(8):1962. https://doi.org/10.2337/diacare.27.8.1962.

10. Son J-W, Jang E-H, Kim M-K, Kim IT, Roh YJ, Baek K-H, et al. Diabetic retinopathy is associated with subclinical atherosclerosis in newly diagnosed type 2 diabetes mellitus. Diabetes Res Clin Pr. 2011;91(2):253-9. https:// doi.org/10.1016/j.diabres.2010.11.005.

11. Bolinger MT, Antonetti DA. Moving past anti-VEGF: novel therapies for treating diabetic retinopathy. Int J Mol Sci. 2016;17(9):1-23. https://doi. org/10.3390/ijms17091498.

12. Keech AC, Mitchell P, Summanen PA, O'Day J, Davis TME, Moffitt MS, et al. Effect of fenofibrate on the need for laser treatment for diabetic retinopathy (FIELD study): a randomised controlled trial. Lancet. 2007;370(9600):1687-97. https://doi.org/10.1016/S0140-6736(07)61607 $-9$

13. ACCORD Study Group, ACCORD Eye Study Group, Chew EY, Ambrosius WT, Davis MD, Danis RP, et al. Effects of medical therapies on retinopathy progression in type 2 diabetes. N Engl J Med. 2010;363(3):233-44. https:// doi.org/10.1056/nejmoa1001288.

14. Cobble M, Bale B. Carotid intima-media thickness: knowledge and application to everyday practice. Postgrad Med. 2010;122(1):10-8. https://doi. org/10.3810/pgm.2010.01.2091.

15. Ratchford EV, Evans NS. Carotid artery disease. Vasc Med. 2014;19(6):5125. https://doi.org/10.1177/1358863X14557722.

16. Touboul PJ, Hennerici MG, Meairs S, Adams H, Amarenco P, Desvarieux $M$, et al. Mannheim intima-media thickness consensus. Cerebrovasc Dis. 2004;18(4):346-9. https://doi.org/10.1159/000081812.

17. Bots ML, Dijk JM, Oren A, Grobbee DE. Carotid intima-media thickness, arterial stiffness and risk of cardiovascular disease: current evidence. J Hypertens. 2002;20(12):2317-25.

18. Naqvi TZ, Lee M-S. Carotid intima-media thickness and plaque in cardiovascular risk assessment. JACC Cardiovasc Imaging. 2014;7(10):1025-38. https://doi.org/10.1016/j.jcmg.2013.11.014.

19. Krentz AJ, Clough G, Byrne CD. Interactions between microvascular and macrovascular disease in diabetes: pathophysiology and therapeutic implications. Diabetes Obes Metab. 2007;9(6):781-91. https://doi.org/10.1 111/j.1463-1326.2007.00670.x.

20. Moher D, Liberati A, Tetzlaff J, Altman DG, Group P. Preferred reporting items for systematic reviews and meta-analyses: the PRISMA statement. PLoS Med. 2009;6(7):1-6. https://doi.org/10.1371/journal.pmed.1000097.

21. Higgins J, Thomas J, Chandler J, Cumpston M, Li T, Page M, et al., (editors). Cochrane handbook for systematic reviews of interventions version 6.0 (updated July 2019). Cochrane 2019. http://www.training.cochrane.org/ handbook. Accessed 2 Sept 2019.

22. National Heart Lung and Blood Institute. Study Quality Assessment Tools https://www.nhlbi.nih.gov/health-topics/study-quality-assessment-tools. Accessed 21 Oct 2019.

23. Cardoso CRL, Salles GC, Leite NC, Salles GF. Prognostic impact of carotid intima-media thickness and carotid plaques on the development of micro- and macrovascular complications in individuals with type 2 diabetes: the Rio de Janeiro type 2 diabetes cohort study. Cardiovasc Diabetol. 2019;18(2):1-13. https://doi.org/10.1186/s12933-019-0809-1.
24. Gül K, Üstün Ý, Aydýn Y, Berker D, Erol K, Ünal M, et al. Carotid intimamedia thickness and its relations with the complications in patients with type 1 diabetes mellitus. Anatol J Cardiol. 2010;10(1):52-8.

25. Kocaoglu I, Kocaoglu E, Arslan U, Balci MM, Vural M, Alp MN, et al. Relationship between retinopathy and asymptomatic atherosclerosis determined by measurement of carotid intima-media thickness in patients with type 2 diabetes mellitus. Turk Kardiyol Dern Ars. 2015;44(1):24-9. https://doi.org/10.5543/tkda.2015.69313.

26. Malecki MT, Osmenda G, Walus-Miarka M, Skupien J, Cyganek K, Mirkiewicz-Sieradzka B, et al. Retinopathy in type 2 diabetes mellitus is associated with increased intima-media thickness and endothelial dysfunction. Eur J Clin Invest. 2008;38(12):925-30. https://doi.org/10.111 1/j.1365-2362.2008.02051.x.

27. Jung C-H, Baek A-R, Kim K-J, Kim B-Y, Kim C-H, Kang S-K, et al. Association between cardiac autonomic neuropathy, diabetic retinopathy and carotid atherosclerosis in patients with type 2 diabetes. Endocrinol Metab. 2013;28(4):309-19.

28. Alonso N, Traveset A, Rubinat E, Ortega E, Alcubierre N, Sanahuja J, et al. Type 2 diabetes-associated carotid plaque burden is increased in patients with retinopathy compared to those without retinopathy. Cardiovasc Diabetol. 2015;14(33):1-9. https://doi.org/10.1186/s12933-015-0196-1.

29. Cardoso CR, Marques CE, Leite NC, Salles GF. Factors associated with carotid intima-media thickness and carotid plaques in type 2 diabetic patients. J Hypertens. 2012;30(5):940-7. https://doi.org/10.1097/ HJH.0b013e328352aba6.

30. Araszkiewicz A, Rogowicz-Frontczak A, Zozulinska-Ziolkiewicz D, Pilacinski S, Wykretowicz A, Wierusz-Wysocka B. Presence of retinopathy in type 1 diabetic patients is associated with subclinical macroangiopathy. Scand J Clin Lab Invest. 2011;71(7):563-8. https://doi.org/10.3109/00365 513.2011.593268.

31. Distiller LA, Joffe BI, Melville V, Welman T, Distiller GB. Carotid artery intima-media complex thickening in patients with relatively long-surviving type 1 diabetes mellitus. J Diabetes Complicat. 2006;20(5):280-4. https://doi.org/10.1016/j.jdiacomp.2005.07.012.

32. Hjelmgren O, Stromberg U, Gellerman K, Thurin A, Zetterberg M, Bergstrom G. Does retinopathy predict stroke recurrence in type 2 diabetes patients: a retrospective study? PLoS ONE. 2019;14(1):e0210832. https:// doi.org/10.1371/journal.pone.0210832.

33. Lacroix P, Aboyans V, Criqui MH, Bertin F, Bouhamed T, Archambeaud F, et al. Type-2 diabetes and carotid stenosis: a proposal for a screening strategy in asymptomatic patients. Vasc Med. 2006;11(2):93-9. https://doi. org/10.1191/1358863x06vm677oa.

34. Liu Y, Teng X, Zhang W, Zhang R, Liu W. Association between diabetic retinopathy and subclinical atherosclerosis in China: results from a community-based study. Diab Vasc Dis Res. 2015;12(5):366-72. https:// doi.org/10.1177/1479164115591744.

35. Zhu X-R, Zhang Y-P, Bai L, Zhang X-L, Zhou J-B, Yang J-K. Prediction of risk of diabetic retinopathy for all-cause mortality, stroke and heart failure: evidence from epidemiological observational studies. Medicine. 2017;96(3):e5894. https://doi.org/10.1097/MD.0000000000005894.

36. Cheung N, Liew G, Wong TY. Current approaches to retinopathy as a predictor of cardiovascular risk. In: Hammes H-P, Porta M, editors. Experimental Approaches to Diabetic Retinopathy. 20. Basel, Switzerland: Karger; 2009. p. 203-19.

37. Gerstein HC, Ambrosius WT, Danis R, Ismail-Beigi F, Cushman W, Calles J, et al. Diabetic retinopathy, its progression, and incident cardiovascular events in the ACCORD trial. Diabetes Care. 2013;36(5):1266-71. https:// doi.org/10.2337/dc12-1311.

38. Pena AS, Liew G, Anderson J, Giles LC, Gent R, Wong TY, et al. Early atherosclerosis is associated with retinal microvascular changes in adolescents with type 1 diabetes. Pediatr diabetes. 2018;19(8):1467-70. https://doi. org/10.1111/pedi.12764.

39. Tang J, Li T, Li P, Ma Y, Liu M, Shan Q, et al. Early assessment of the risk factors for diabetic retinopathy can reduce the risk of peripheral arterial and cardiovascular diseases in type 2 diabetes. Ophthalmic Res. 2018:59(4):221-7. https://doi.org/10.1159/000479931.

40. Pease A, Earnest A, Ranasinha S, Nanayakkara N, Liew D, Wischer N, et al. Burden of cardiovascular risk factors and disease among patients with type 1 diabetes: results of the Australian National Diabetes Audit (ANDA). Cardiovasc Diabetol. 2018;17(1):77. https://doi.org/10.1186/s1293 3-018-0726-8. 
41. Zhang X, Lim SC, Tavintharan S, Yeoh LY, Sum CF, Ang K, et al. Association of central arterial stiffness with the presence and severity of diabetic retinopathy in Asians with type 2 diabetes. Diab Vasc Dis Res. 2019;16(6):498-505. https://doi.org/10.1177/1479164119845904.

42. de Kreutzenberg SV, Coracina A, Volpi A, Fadini GP, Frigo AC, Guarneri $\mathrm{G}$, et al. Microangiopathy is independently associated with presence, severity and composition of carotid atherosclerosis in type 2 diabetes. Nutr Metab Cardiovasc Dis. 2011;21(4):286-93. https://doi.org/10.1016/j. numecd.2009.10.003.

43. Slieker RC, van der Heijden AA, Nijpels G, et al. Visit-to-visit variability of glycemia and vascular complications: the Hoorn Diabetes Care System cohort. Cardiovasc Diabetol. 2019;18(1):170-213. https://doi.org/10.1186/ s12933-019-0975-1.

44. Arcidiacono MV, Traveset A, Rubinat E, Ortega E, Betriu A, Hernandez M, et al. Microangiopathy of large artery wall: a neglected complication of diabetes mellitus. Atherosclerosis. 2013;228(1):142-7. https://doi. org/10.1016/j.atherosclerosis.2013.02.011.

45. Langheinrich AC, Kampschulte M, Buch T, Bohle RM. Vasa vasorum and atherosclerosis—Quid novi? Thromb Haemost. 2007;97(6):873-9. https:// doi.org/10.1160/TH06-12-0742.
46. Orasanu G, Plutzky J. The pathologic continuum of diabetic vascular disease. J Am Coll Cardiol. 2009;53(5 Suppl):S35-42. https://doi. org/10.1016/j.jacc.2008.09.055.

47. Howard RS, Russell RW. Prognosis of patients with retinal embolism. J Neurol Neurosurg Psychiatry. 1987;50(9):1142-7. https://doi.org/10.1136/ jnnp.50.9.1142.

48. Lahme L, Marchiori E, Panuccio G, Nelis P, Schubert F, Mihailovic N, et al. Changes in retinal flow density measured by optical coherence tomography angiography in patients with carotid artery stenosis after carotid endarterectomy. Sci Rep. 2018;8(17161):1-6. https://doi.org/10.1038/ s41598-018-35556-4.

49. Yan J, Yang X, Wu J, Liu B, Jiao X, Li W, et al. Visual outcome of carotid endarterectomy in patients with carotid artery stenosis. Ann Vasc Surg. 2019;58:347-56. https://doi.org/10.1016/j.avsg.2018.12.069.

\section{Publisher's Note}

Springer Nature remains neutral with regard to jurisdictional claims in published maps and institutional affiliations.
Ready to submit your research? Choose BMC and benefit from:

- fast, convenient online submission

- thorough peer review by experienced researchers in your field

- rapid publication on acceptance

- support for research data, including large and complex data types

- gold Open Access which fosters wider collaboration and increased citations

- maximum visibility for your research: over $100 \mathrm{M}$ website views per year

At BMC, research is always in progress.

Learn more biomedcentral.com/submissions 